\title{
BMJ Open Prevalence of domestic violence against women in informal settlements in Mumbai, India: a cross-sectional survey
}

\author{
Nayreen Daruwalla, ${ }^{1}$ Suman Kanougiya, ${ }^{1}$ Apoorwa Gupta, ${ }^{1}$ Lu Gram (D) , \\ David Osrin (1) ${ }^{2}$
}

To cite: Daruwalla $\mathrm{N}$, Kanougiya S, Gupta A, et al. Prevalence of domestic violence against women in informal settlements in Mumbai, India: a crosssectional survey. BMJ Open 2020;10:e042444. doi:10.1136/ bmjopen-2020-042444

- Prepublication history for this paper is available online. To view these files, please visit the journal online (http://dx.doi. org/10.1136/bmjopen-2020042444).

Received 06 July 2020

Revised 09 November 2020

Accepted 24 November 2020

Check for updates

(c) Author(s) (or their employer(s)) 2020. Re-use permitted under CC BY. Published by BMJ.

${ }^{1}$ Programme on Prevention of Violence Against Women and Children, Society for Nutrition, Education and Health Action (SNEHA), Mumbai, Maharashtra, India

${ }^{2}$ Institute for Global Health, University College London, London, UK

Correspondence to

Dr David Osrin;

d.osrin@ucl.ac.uk

\section{ABSTRACT}

Objectives Domestic violence against women harms individuals, families, communities and society. Perpetrated by intimate partners or other family members, its overlapping forms include physical, sexual and emotional violence, control and neglect. We aimed to describe the prevalence of these forms of violence and their perpetrators in informal settlements in Mumbai.

Design Cross-sectional survey.

Setting Two large urban informal settlement areas.

Participants 5122 women aged 18-49 years.

Primary and secondary outcome measures Prevalence and perpetrators in the last year of physical, sexual and emotional domestic violence, coercive control and neglect. For each of these forms of violence, responses to questions about individual acts and composite estimates. Results In the last year, 644 (13\%) women had experienced physical domestic violence, $188(4 \%)$ sexual violence and $963(19 \%)$ emotional violence. Of evermarried women, $13 \%$ had experienced physical or sexual intimate partner violence in the last year. Most physical $(87 \%)$ and sexual violence $(99 \%)$ was done by partners, but emotional violence equally involved marital family members. All three forms of violence were more common if women were younger, in the lowest socioeconomic asset quintile or reported disability. 1816 women (35\%) had experienced at least one instance of coercive control and $33 \%$ said that they were afraid of people in their home. $10 \%$ reported domestic neglect of their food, sleep, health or children's health.

Conclusions Domestic violence against women remains common in urban informal settlements. Physical and sexual violence were perpetrated mainly by intimate partners, but emotional violence was attributed equally to partners and marital family. More than one-third of women described controlling behaviours perpetrated by both intimate partners and marital family members. We emphasise the need to include the spectrum of perpetrators and forms of domestic violence-particularly emotional violence and coercive control—in data gathering.

Trial registration number ISRCTN84502355; Pre-results.

\section{BACKGROUND}

The global burden of domestic violence is underlined by its inclusion as an indicator of gender equality for the fifth United Nations

\section{Strengths and limitations of this study}

A large cross-sectional survey of women in informal settlements.

- The study included emotional violence, coercive control and neglect, as well as physical and sexual domestic violence against women.

- The study considered perpetrators of violence other than intimate partners.

- The cross-sectional nature of the study limited the possibility of causal inference.

Sustainable Development Goal (https:// sdg-tracker.org/gender-equality). Domestic violence against women harms individuals, families, communities and society. For individuals, it causes injury or death, ${ }^{12}$ reproductive health problems, harmful drug and alcohol use, anxiety, depression, post-traumatic stress disorder, self-harm and suicide. ${ }^{13}$ For families, it leads to miscarriage, induced abortion, stillbirth, low birth weight, preterm delivery and further violence. ${ }^{45}$ For communities and society, it leads to lack of agency, limited participation and lost economic productivity. $^{56}$

Globally, $30 \%$ of women have survived physical or sexual violence by an intimate partner or sexual violence by a non-partner. ${ }^{4}$ The precision of the wording of this statement illustrates the challenge of defining violence against women. The United Nations Declaration on the Elimination of Violence Against Women defines it as 'any act of gender-based violence that results in, or is likely to result in, physical, sexual or psychological harm or suffering to women, including threats of such acts, coercion or arbitrary deprivation of liberty, whether occurring in public or in private life'. ${ }^{7}$ This definition allows for a range of perpetrators and a range of forms of violence. The perpetrator may be a husband or partner (intimate partner violence), a family or household member, or someone known 


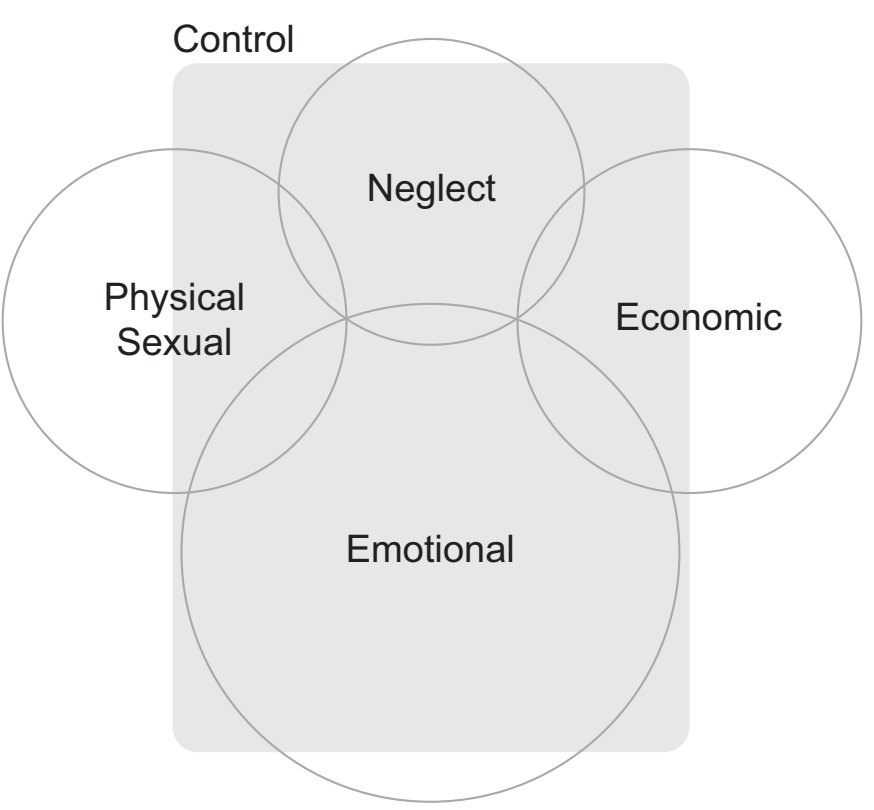

Figure 1 Forms of domestic violence against women.

or unknown outside the domestic environment (in this paper, we define domestic violence as falling into either or both of the first two categories). Figure 1 conceptualises the intersecting forms of domestic violence: physical, sexual, emotional or psychological, control, neglect, or economic. These forms of violence overlap and occur in combination, in some settings with forms such as female genital mutilation and modern slavery.

There is consensus that measuring the scope and prevalence of violence against women is important, and that we should try to measure its different sources and forms. ${ }^{8}$ Doing so may help identify the harm it can cause, advocate on behalf of individual women and against an unacceptable societal burden of coercive control (a perspective that owes much to the work of feminists over the last half century) and compare research findings across time and place and in a shared language. ${ }^{9}$ We should be aware, however, that an emphasis on definition and metrics is characteristic of a public health approach. ${ }^{10}$ As feminists have emphasised, violence against women is equally a human rights and criminal justice concern, ${ }^{11}$ the product of an ecology of micro, meso and macro factors ${ }^{12}$ and a manifestation of structural violence and gendered power imbalances. Too tight a focus on its epidemiology might depoliticise violence against women and shift attention away from these issues. ${ }^{13}$

Surveys have been important in international efforts to establish prevalence, the most prominent being the WHO multicountry study on women's health and domestic violence against women ${ }^{14}$ and the International Violence Against Women Survey. ${ }^{15}$ Choosing and comparing between the available scales and questionnaires is difficult. ${ }^{1617}$ The challenges to measurement are substantial, ${ }^{18}$ not least in terms of definitions and terminology. ${ }^{19}$ Early surveys focused on intimate partner physical violence. The Conflict Tactics Scale, ${ }^{20}$ on which they have often been based, has been extended to include sexual and emotional violence, ${ }^{21}$ and the definition has been extended to include perpetrators other than intimate partners. ${ }^{22}$ Whatever has been achieved in terms of definitions and scales, a fundamental challenge remains disclosure: women may not perceive, acknowledge or communicate that they are surviving violence. ${ }^{2324}$ This is a central issue for clinical and social service provision, ${ }^{25-29}$ makes crime and hospital records difficult to use in estimating prevalence and extends to interviews in surveys.

India is a signatory to the Convention on the Elimination of All Forms of Discrimination Against Women. ${ }^{30}$ Violence against women is addressed by criminal law, particularly domestic violence in Section 498-A of the Indian Penal Code, and by civil law in the form of the Protection of Women from Domestic Violence Act, 2005, which encompasses the varied forms of domestic violence and its perpetrators (available at https://indiacode.nic. in/bitstream/123456789/2021/1/200543.pdf). A systematic review of 137 studies suggested that $22 \%$ of women in India had survived physical violence in the past year (131 studies), 22\% had suffered emotional or verbal psychological violence (60 studies), 7\% sexual violence (79 studies) and $30 \%$ multiple forms of violence. ${ }^{31}$ Women in India also commonly experience forms of violence that extend to coercive control and neglect, ${ }^{32}$ articulated in the idea of gender-based household maltreatment ${ }^{33}$ and captured in the recent Indian Family Violence and Control Scale. ${ }^{34}$

We work on primary, secondary and tertiary prevention of violence against women in informal settlements in Mumbai. The prevalence of physical and emotional violence in such settings has been reported as high. ${ }^{35-38}$ At the beginning of a programme of community mobilisation to prevent violence against women and girls, we conducted a baseline survey. Our objectives in this analysis were to estimate the prevalence of physical, sexual and emotional violence, control and neglect. We were particularly interested in sources of domestic violence other than intimate partners and in forms of violence other than physical.

\section{METHODS \\ Setting}

One in four of the world's urban residents live in informal settlements (slums), ${ }^{39}$ characterised by overcrowding, insubstantial housing, insufficient water and sanitation, lack of tenure and hazardous location. ${ }^{40}$ In India, the state of Maharashtra accounts for $18 \%$ of the national total: more than 100 million residents. ${ }^{41}$ Just over $40 \%$ of Mumbai homes are in informal settlements. The Census of India describes these as areas in which dwellings are unfit for human habitation as a result of dilapidation, overcrowding and poor building and street design, with associated poor ventilation, light and sanitation. ${ }^{42}$

The Society for Nutrition, Education and Health Action (SNEHA) is a non-government organisation working to improve health in such settlements. The 
SNEHA programme on Prevention of Violence Against Women and Children began in 2000. Primary prevention is addressed through a combination of community group activities and resulting individual voluntarism. Secondary prevention includes local crisis response and psychological first aid by community organisers and referral to centres which provide counselling, legal and psychotherapeutic support, with links to the police and medical, shelter and social service providers. Tertiary prevention is provided primarily through referral to psychiatric and legal services. Having satisfied criteria for counselling, shelter, legal aid and access to medical care, SNEHA is a service provider under the Protection of Women from Domestic Violence Act, 2005, and is authorised to file domestic incident reports. Under the Protection of Children from Sexual Offences Act, 2012, SNEHA has reporting rights to the police and Child Welfare Committee.

\section{Design}

We did a cross-sectional survey of women's experience of violence, collected at the beginning of a cluster randomised controlled trial of community interventions to prevent violence against women and girls (the SNEHATARA trial) ${ }^{43}$

\section{Sample size}

We aimed to complete approximately 100 questionnaires in each of 50 clusters, giving a total sample of around 5000. An estimate of prevalence from a cross-sectional sample of 5000 in a population of 125000 would have a precision of $\sim 1 \%$. Within this, a comparison of two categories of determinant for 100 respondents in each of 50 clusters would provide $80 \%$ power to detect a difference of $6 \%$ in prevalence estimates of $10 \%-20 \%$.

\section{Sampling process}

Potential clusters were identified in four phases in two areas of the city, and 50 were selected on the basis of (A) vulnerability assessed against a scorecard, ${ }^{44}$ (B) no known plans for rehabilitation or demolition in the next 2 years, (C) absence of existing non-government organisation programmes addressing violence against women, (D) more than $75 \%$ of structures residential and less than $25 \%$ rental, and (E) clear separation from each other.

\section{Data collection}

Structures and homes within clusters were mapped and 16 female interviewers with graduate education and 3 months of training visited households to enumerate residents and list possible participants. Interviewers began at a random start point and visited every second household to enrol participants. Inclusion criteria were that respondents should be women aged 18-49 years who were usual residents. When there was more than one potential respondent in a household, the investigator applied an algorithm that selected the youngest woman at risk of disability, followed by the youngest married woman, followed by the youngest unmarried woman.
The questionnaire included modules on general health and well-being, common mental disorder, household decision-making, household power and control, neglect, experience of economic, emotional, physical and sexual violence, disclosure and support. Questions were taken from existing Hindi versions where possible. If not, they were translated from English, piloted in two clusters external to the trial, amended and back translated.

Interviewers were all women and provided both time and sufficient information for women to consider whether to participate. They were supported by three field supervisors with direct linkage to counselling services, available by phone at any time. The interview team visited the local police station and social services to discuss their activities before starting in each area. Interviewers worked in groups of seven to eight in one cluster at a time, accompanied by a supervisor. A pair worked together in each lane and administered interviews in adjacent households.

To ensure privacy, interviews were arranged by advance appointment and avoided times when partners or children were likely to return from work or school. Women were interviewed at home or in a local community office if they preferred it. The interview began with general questions about demography, household residents, education, socioeconomic position, maternity and health. If a family member, neighbour or friend entered, the interviewer went back to asking questions about general health. If the person showed signs of staying, the interview was terminated and completed over up to three repeat visits. As a result of the gatekeeper consent process, community members were aware that interviewers would be visiting people in their area and this limited curiosity and intrusion.

\section{Data management}

Interviewers used electronic tablets to enter information in a database in CommCare (www.dimagi.com). To optimise accuracy, the system included field constraints, lookup tables and automated skip logic. Mobile connectivity allowed immediate contact between interviewers and supervisors. We examined variation in prevalence rates by interviewer and discussed performance in supervisory meetings. We selected for field observation interviewers who showed signs of deviation from the group average and provided feedback where necessary.

\section{Statistical analysis}

In developing our questionnaire, we aimed to provide data that would allow comparisons between studies and settings. We included questions from major surveys, international and national, and it should be possible to develop summary measures of violence against women using any of a number of combinations of questions. Our idea was to make the resulting anonymised data set available so that others might use it, choosing specific questions to facilitate comparison or pooling of data. Here we present composite indicators of lifetime and 12-month prevalence of physical, sexual and emotional violence. 
Table 1 summarises the questions in three surveys from India (our TARA trial questionnaire, the National Family Health Survey (NFHS-4) ${ }^{45}$ and the Indian Family Violence and Control Scale ${ }^{34}$ ) and two international surveys (the International Violence Against Women Survey ${ }^{15}$ and the WHO multicountry study ${ }^{14}$ ).

Our composite estimate of prevalence of physical violence included nine questions that were comparable across surveys, although there was variation in whether threats of violence were considered incidents of physical violence. The estimate of prevalence of domestic sexual violence included four questions. The comparable questions about sexual violence were similar, although only the TARA survey and the Indian Family Violence Survey included a question on coercion to replicate activities seen in pornographic materials. The estimate of prevalence of domestic emotional violence included five questions that were comparable across surveys. We asked a series of questions about domestic coercive control, addressing mobility, education, employment, appearance and pregnancy. For control and neglect, we present the individual questions because composite indicators are not yet established.

We used the Washington Group Short Set on Functioning questions to identify disability, including difficulty with seeing, hearing, walking, remembering, self-care and speaking (http://www.washingtongroup-disability.com/ washington-group-question-sets/short-set-of-disabilityquestions/). We took the most permissive of four possible approaches to classification, in which disability is registered if the respondent reports at least some difficulty in at least one of the six domains. ${ }^{46}$ We classified socioeconomic position with quintiles of scores derived from standardised weights for the first component of a principal components analysis of 22 individual household assets. ${ }^{47} 48$

Prevalence is summarised by frequency and percentage. We plotted prevalence of physical, sexual and emotional violence in the last year by age group, schooling, socioeconomic asset quintile and disability, collapsed by grouping variable and rounded using the twoway (connected) command in Stata V.15. We calculated ORs for associations using logistic regression and Stata survey commands with cluster as the primary sampling unit and phase as stratum. We calculated intracluster correlation coefficients (ICC) for prevalence of physical, sexual and emotional violence in the last year using the loneway command in Stata V.15. The paper was prepared according to the Strengthening the Reporting of Observational Studies in Epidemiology statement for reports of observational studies (www. strobe-statement.org).

\section{Ethical considerations}

We took permission for the survey from cluster gatekeepers identified by residents, ${ }^{49} 50$ and followed WHO guidelines for research on domestic violence against women, ${ }^{51}$ and on sexual violence. ${ }^{52}$ Participants gave signed consent after discussing a participant information sheet. We made provision for storage of participant information sheets on women's behalf if they were concerned that the paperwork might be seen by others.

Data collectors explained their right to not provide answers to specific questions, to terminate the interview and to withdraw temporarily or permanently without penalty. All team members were trained in Good Clinical Practice for research ethics and participant protection (Scientia Clinical Services, 14 February 2019), and interviewers were supported by three field supervisors with direct linkage to counselling services.

Interviewing women about their possible experience of violence raises issues of consent, interviewer behaviour, privacy and confidentiality. Of particular concern is the duty of care after disclosure. We believe that an interviewee who discloses experience of violence should be offered optimal support, and interviewers were members of a broader team who were able to provide a full suite of crisis and counselling services, including home visits, medical, surgical and psychiatric referral, and negotiation with families, the police and legal representatives. When survivors disclosed violence, we followed established intervention protocols which included safety assessment, counselling, liaison with healthcare, police and legal services, and developing follow-up plans for the survivor and her family. Participants were able to speak with counsellors immediately by phone. When a survivor was not ready to disclose violence, the interviewer provided her with information on available services and legal rights and gave her a small card that was easy to hide and listed essential contact numbers and addresses for 24-hour crisis support, medical emergencies and the police. She took consent for any action from the participant herself.

\section{Patient and public involvement}

Community members have been involved in the design of our research since 2000. It arises from the need to provide and improve services for survivors of violence, and a commitment to working with communities to prevent it. Research questions and outcome measures were derived from international efforts, but client priorities were reflected in some specific questions that we asked as a result of client experiences. All questions were discussed with participants in pilot exercises in order to understand their perceptions and ability to respond. Community guardians were involved in recruitment and the practicalities of administering the survey. Respondents took about an hour to answer the questions, and participated only after consideration. The general findings will be disseminated through community groups involved in ongoing interventions in the study areas.

\section{RESULTS}

\section{Participants}

Between 5 December 2017 and 28 March 2019, a total of 5277 households were approached for the survey. Four hundred and twenty-three (2\%) had no eligible 
Table 1 Comparison of questions in five surveys describing physical, sexual and emotional violence

\begin{tabular}{|c|c|c|c|c|c|}
\hline & $\begin{array}{l}\text { SNEHA- } \\
\text { TARA }\end{array}$ & NFHS- $4^{45}$ & $\begin{array}{l}\text { Indian Family Violence } \\
\text { and Control Scale }{ }^{34}\end{array}$ & $\begin{array}{c}\text { WHO } \\
\text { multicountry } \\
\text { study }^{14}\end{array}$ & $\begin{array}{l}\text { International Violence } \\
\text { Against Women Survey }{ }^{15}\end{array}$ \\
\hline \multicolumn{6}{|l|}{ Physical } \\
\hline Pushed, shoved, shaken, hurt & $\sqrt{ }$ & $\sqrt{ }$ & $\sqrt{ }$ & $\sqrt{ }$ & $\sqrt{ }$ \\
\hline $\begin{array}{l}\text { Twisted arm, banged head, } \\
\text { pulled hair }\end{array}$ & $\sqrt{ }$ & $\sqrt{ }$ & $\sqrt{ }$ & & $\sqrt{ }$ \\
\hline Slapped, pinched, bitten & $\sqrt{ }$ & $\sqrt{ }$ & $\sqrt{ }$ & $\sqrt{ }$ & $\sqrt{ }$ \\
\hline Hit, punched & $\sqrt{ }$ & $\sqrt{ }$ & $\sqrt{ }$ & $\sqrt{ }$ & \\
\hline Kicked, dragged, beaten & $\sqrt{ }$ & $\sqrt{ }$ & $\sqrt{ }$ & $\sqrt{ }$ & \\
\hline Things thrown at, burned & $\sqrt{ }$ & & $\sqrt{ }$ & $\sqrt{ }$ & \\
\hline $\begin{array}{l}\text { Attacked or threatened with } \\
\text { sharp object }\end{array}$ & $\sqrt{ }$ & $\sqrt{ }$ & $\sqrt{ }$ & $\sqrt{ }$ & $\sqrt{ }$ \\
\hline $\begin{array}{l}\text { Attacked or threatened with } \\
\text { blunt object }\end{array}$ & $\sqrt{ }$ & $\sqrt{ }$ & $\sqrt{ }$ & $\sqrt{ }$ & $\sqrt{ }$ \\
\hline $\begin{array}{l}\text { Suffocated, choked, hung, } \\
\text { poisoned }\end{array}$ & $\sqrt{ }$ & $\sqrt{ }$ & $\sqrt{ }$ & $\sqrt{ }$ & $\sqrt{ }$ \\
\hline \multicolumn{6}{|l|}{ Sexual } \\
\hline Forced intercourse & $\sqrt{ }$ & $\sqrt{ }$ & $\sqrt{ }$ & $\sqrt{ }$ & $\sqrt{ }$ \\
\hline Forced other degrading act & $\sqrt{ }$ & $\sqrt{ }$ & $\sqrt{ }$ & $\sqrt{ }$ & \\
\hline Threatened other act & $\sqrt{ }$ & $\sqrt{ }$ & & & \\
\hline Forced to replicate pornography & $\sqrt{ }$ & & $\sqrt{ }$ & & \\
\hline Forced sex during menses & $\sqrt{ }$ & & $\sqrt{ }$ & & \\
\hline Forced sex with someone else & $\sqrt{ }$ & & $\sqrt{ }$ & & \\
\hline $\begin{array}{l}\text { Forced sex without } \\
\text { contraception }\end{array}$ & $\sqrt{ }$ & & $\sqrt{ }$ & & \\
\hline $\begin{array}{l}\text { Threatened sex with another } \\
\text { person }\end{array}$ & $\sqrt{ }$ & & $\sqrt{ }$ & & \\
\hline Forced video of sex & $\sqrt{ }$ & & $\sqrt{ }$ & & \\
\hline $\begin{array}{l}\text { Taken advantage of when } \\
\text { drugged or drunk }\end{array}$ & $\sqrt{ }$ & & $\sqrt{ }$ & & \\
\hline Forced to watch pornography & $\sqrt{ }$ & & & & \\
\hline Insisted on repeated intercourse & $\sqrt{ }$ & & & & \\
\hline $\begin{array}{l}\text { Forced to entertain others } \\
\text { sexually }\end{array}$ & $\sqrt{ }$ & & & & \\
\hline Forced drugs or alcohol for sex & $\sqrt{ }$ & & & & \\
\hline Partner withheld sexual pleasure & $\sqrt{ }$ & & & & \\
\hline \multicolumn{6}{|l|}{ Emotional } \\
\hline $\begin{array}{l}\text { Insulted, made to feel bad about } \\
\text { herself }\end{array}$ & $\sqrt{ }$ & $\sqrt{ }$ & $\sqrt{ }$ & $\sqrt{ }$ & \\
\hline $\begin{array}{l}\text { Belittled, humiliated in front of } \\
\text { others }\end{array}$ & $\sqrt{ }$ & $\sqrt{ }$ & $\sqrt{ }$ & $\sqrt{ }$ & \\
\hline Ignored, treated indifferently & $\sqrt{ }$ & & $\sqrt{ }$ & $\sqrt{ }$ & \\
\hline $\begin{array}{l}\text { Scared or intimidated on } \\
\text { purpose }\end{array}$ & $\sqrt{ }$ & & $\sqrt{ }$ & $\sqrt{ }$ & \\
\hline $\begin{array}{l}\text { Threatened to hurt her, someone } \\
\text { close, or take child away }\end{array}$ & $\sqrt{ }$ & $\sqrt{ }$ & & $\sqrt{ }$ & $\sqrt{ }$ \\
\hline Insulted for not having a baby & $\sqrt{ }$ & & $\sqrt{ }$ & & \\
\hline Insulted for not having a son & $\sqrt{ }$ & & $\sqrt{ }$ & & \\
\hline
\end{tabular}

Continued 


\begin{tabular}{|c|c|c|c|c|c|}
\hline & $\begin{array}{l}\text { SNEHA- } \\
\text { TARA }\end{array}$ & NFHS- $4^{45}$ & $\begin{array}{c}\text { Indian Family Violence } \\
\text { and Control Scale }\end{array}$ & $\begin{array}{c}\text { WHO } \\
\text { multicountry } \\
\text { study }^{14}\end{array}$ & $\begin{array}{c}\text { International Violence } \\
\text { Against Women Survey }^{15}\end{array}$ \\
\hline Afraid of family members & $\sqrt{ }$ & & & & \\
\hline Accused of infidelity & $\sqrt{ }$ & $\sqrt{ }$ & & $\sqrt{ }$ & \\
\hline Insulted for being a woman & $\sqrt{ }$ & & & & \\
\hline
\end{tabular}

NFHS, National Family Health Survey; SNEHA, Society for Nutrition, Education and Health Action; TARA, Taking Action Reaching All.

female resident and in $544(3 \%)$ an eligible woman was unavailable after three visits. Interviewers were unable to achieve privacy in 592 cases $(11 \%)$ and $155(3 \%)$ potential respondents declined the interview. The final survey included 5122 respondents. A median of 101 interviews were achieved in each cluster (IQR 100-103; range 94-118).

Table 2 summarises the characteristics of households, respondents and their partners. Dwellings were generally of robust or mixed robust and insubstantial construction (93\%). Only $17 \%$ had their own toilet. Respondents were predominantly of Hindu (59\%) or Muslim (37\%) faith and $58 \%$ described themselves as of general caste. Sixtyeight per cent of women had been born outside Mumbai, $96 \%$ had been married or partnered, $2 \%$ had separated or divorced and $2 \%$ had been widowed. Thirty-six per cent had married before the age of 18 years, $88 \%$ of them by arrangement, $14 \%$ had had a pregnancy before the age of 18 years and $36 \%$ had three children or more. Women were a mean of 32 years old (SD 7.3) and their partners a mean of 36 (SD 8.1). Eighteen per cent of women had had no schooling, compared with $10 \%$ of partners, and $36 \%$ had completed high school, compared with $48 \%$ of partners. Only $24 \%$ of women had undertaken paid work in the last year, compared with $98 \%$ of men. For these women, the main types of employment were home based $(62 \%)$, informal or formal services (17\%) and domestic labour $(10 \%)$. The main types of employment for men were in informal or formal services $(49 \%)$ or as drivers $(18 \%)$.

\section{Domestic physical violence}

Table 3 presents lifetime and 12-month prevalence of domestic violence. It includes individual questions and composite estimates for physical (nine questions), sexual (four questions) and emotional violence (five questions). Twenty-five per cent of women had ever experienced domestic physical violence and 13\% had experienced it in the last year. This was usually intimate partner violence $(11 \%)$, but $2 \%$ had experienced physical violence from their marital family and $2 \%$ from their natal family. Around $4 \%$ of women had been kicked, dragged or beaten in the last year, and around $3 \%$ had been threatened or attacked with a blunt or sharp object.

\section{Domestic sexual violence}

Six per cent of women had ever experienced domestic sexual violence and $4 \%$ had experienced it in the last year, almost all by their intimate partner. Removing the question about coercion to replicate pornography from the composite estimate reduced the estimated prevalence of sexual violence by $0.1 \%$ (domestic sexual violence to $5.4 \%$ ever (274 reports) and $3.5 \%$ in the last year (179), and intimate partner sexual violence to $5.1 \%$ ever (262) and $3.5 \%$ in the last year (177)). Additional questions suggested that $2.5 \%$ of partners had insisted on repeated intercourse (126 women in the last year), that $1.1 \%$ of wives had been forced to view pornography (56) that $0.8 \%$ had been subjected to coercive sex without contraception (39) and that $1.0 \%$ of partners were reported as withholding sexual pleasure from their wives (49). The prevalence of domestic physical or sexual violence in the last 12 months was $14 \%$ for currently married women, but $29 \%$ for women who had separated from their partner.

\section{Domestic emotional violence}

Nineteen per cent of women had experienced emotional violence in the last year. The source was roughly evenly split between intimate partner $(12 \%)$ and marital family members $(11 \%)$. Emotional violence came from both intimate partner and marital family for $5 \%$ of women. Six per cent of women had been accused of infidelity, $6 \%$ had been insulted for being a woman and $8 \%$ of 505 women with disability had been insulted for it.

\section{Summary figures}

Limiting the data set to 4913 ever-married women for comparison with surveys such as the NFHS, the prevalence of domestic physical violence in the last 12 months was $13 \%$, of sexual violence $4 \%$, of physical or sexual violence $14 \%$ and of emotional violence $19 \%$. Recent guidance suggests that studies present the proportion of everpartnered women and girls aged 15 years and older who have survived physical, sexual or psychological violence by an intimate partner in the last year. ${ }^{53}$ For intimate partner violence (a subgroup within domestic violence) our findings were $11 \%$ for physical violence, $4 \%$ for sexual, $13 \%$ for emotional (psychological), 13\% for physical or sexual and $17 \%$ for physical, sexual or emotional violence.

Figure 2 shows prevalence of physical, sexual and emotional violence for each of 50 clusters. The ranges 
Table 2 Characteristics of households, respondents and their partners

\begin{tabular}{|c|c|c|c|}
\hline Household & $\mathbf{n}$ & $\%$ & \\
\hline \multicolumn{4}{|l|}{ Fabric } \\
\hline $\begin{array}{l}\text { Kachha } \\
\text { (insubstantial) }\end{array}$ & 353 & \multicolumn{2}{|l|}{7} \\
\hline Mixed & 2149 & \multicolumn{2}{|l|}{42} \\
\hline Pukka (robust) & 2620 & \multicolumn{2}{|l|}{51} \\
\hline \multicolumn{4}{|l|}{ Toilet } \\
\hline Private & 875 & \multicolumn{2}{|l|}{17} \\
\hline Public or charity & 4245 & \multicolumn{2}{|l|}{83} \\
\hline Open defecation & 2 & \multicolumn{2}{|l|}{0} \\
\hline \multicolumn{4}{|l|}{ Religion } \\
\hline Hindu & 3002 & \multicolumn{2}{|l|}{59} \\
\hline Muslim & 1902 & \multicolumn{2}{|l|}{37} \\
\hline Buddhist & 158 & \multicolumn{2}{|l|}{3} \\
\hline Other & 60 & \multicolumn{2}{|l|}{1} \\
\hline All & 5122 & \multicolumn{2}{|l|}{100} \\
\hline \multirow[t]{2}{*}{ Individual } & \multicolumn{2}{|c|}{$\begin{array}{l}\text { Female } \\
\text { respondent }\end{array}$} & $\begin{array}{l}\text { Husband or } \\
\text { partner }\end{array}$ \\
\hline & $\mathbf{n}$ & $\%$ & $\mathbf{n}$ \\
\hline
\end{tabular}

\begin{tabular}{|lrrrr|}
\hline Age group (years) & & & & \\
\hline $18-19$ & 115 & 2 & 14 & 0 \\
\hline $20-29$ & 2038 & 40 & 920 & 19 \\
\hline $30-39$ & 2056 & 40 & 2108 & 44 \\
\hline $40-49$ & 913 & 18 & 1372 & 29 \\
\hline $50+$ & & & 391 & 8 \\
\hline Education & & & & \\
\hline None & 947 & 18 & 474 & 10 \\
\hline Primary 1-5 years & 859 & 17 & 590 & 12 \\
\hline Middle 6-8 years & 1122 & 22 & 981 & 20 \\
\hline High 9-10 years & 1158 & 23 & 1543 & 32 \\
\hline Senior 11-12 years & 572 & 11 & 698 & 15 \\
\hline Undergraduate & 363 & 7 & 371 & 8 \\
\hline Postgraduate & 100 & 2 & 123 & 3 \\
\hline Other & 1 & 0 & 25 & 1 \\
\hline
\end{tabular}

Paid work in the last 12 months

\begin{tabular}{lrrrr} 
Yes & 1252 & 24 & 4697 & 98 \\
No & 3870 & 76 & 108 & 2 \\
All & 5122 & 100 & 4805 & 100 \\
\hline
\end{tabular}

were substantial: for physical violence 2\%-27\% (IQR $12 \%-16 \%$ ), for sexual violence $0 \%-8 \%$ (IQR 2\%-5\%) and for emotional violence 7\%-32\% (IQR 15\%-23\%). ICCs were 0.023 for domestic physical violence in the last year (95\% CI 0.011 to 0.036 ), 0.005 for sexual violence (95\% CI 0.000 to 0.010 ) and 0.016 for emotional violence (95\% CI 0.006 to 0.026 ).
Figure 3 summarises prevalence of physical, sexual and emotional violence by age group, schooling, socioeconomic asset quintile and disability. Women were less likely to face physical and emotional violence as they aged: the prevalence of physical violence halved between the 20s and the 40s. There was no obvious pattern for schooling. All three forms of violence were more common against women in the lowest socioeconomic asset quintile and against women with disability. The ORs in figure 3 did not change substantially when all four covariates were included in multivariable models, apart from disability, which was associated with an adjusted OR of 1.68 (95\% CI 1.24 to 2.29) for physical violence, 2.18 (95\% CI 1.37 to 3.47 ) for sexual violence and 1.66 (95\% CI 1.31 to 2.12) for emotional violence.

\section{Domestic coercive control}

Table 4 summarises forms and sources of coercive control. We took a conservative approach to classifying controlling behaviour. A restrictive behaviour was registered only if it was reported as always occurring, and a permissive behaviour only if it was reported as never occurring. Overall, 1816 women reported being subject to at least one controlling behaviour in the list in table 4 (35\%), although we recorded responses to a larger set of questions. Respondents commonly reported that their mobility and socialising were restricted: $26 \%$ said that they always required permission to go out, $14 \%$ that they were never allowed out in the evening and $10 \%$ that they were always accompanied when they did go out. Forty-eight per cent were never allowed to meet with male friends, $10 \%$ were never allowed to meet with female friends and $5 \%$ were never allowed to meet their natal family. At home, 33\% of women said that they were afraid of family members. Thirteen per cent were never free to speak on the phone and $10 \%$ were never able to speak freely in the home. These kinds of restrictions were described as coming more often from marital family members than from partners. In terms of sexual and reproductive health, 52 women had been denied access to contraception and 15 had been coerced to use it. Thirty-seven (1\% of 4577) had been prevented from having a termination of pregnancy while $15(0.3 \%)$ had been coerced to have one.

\section{Domestic neglect}

Seven per cent of women reported that their family had neglected their food in the last year, $8 \%$ that they had neglected their sleep, $8 \%$ that they had neglected their health and $12 \%$ of 4375 with children that they had neglected their children's health. Collectively, $10 \%$ of women reported at least one of these four dimensions of neglect.

\section{Disclosure of violence}

Of 1153 women who had survived physical, sexual or emotional domestic violence in the last year, $47 \%$ had disclosed to someone. The main confidants were family and friends $(40 \%)$ and teachers, faith leaders or local 


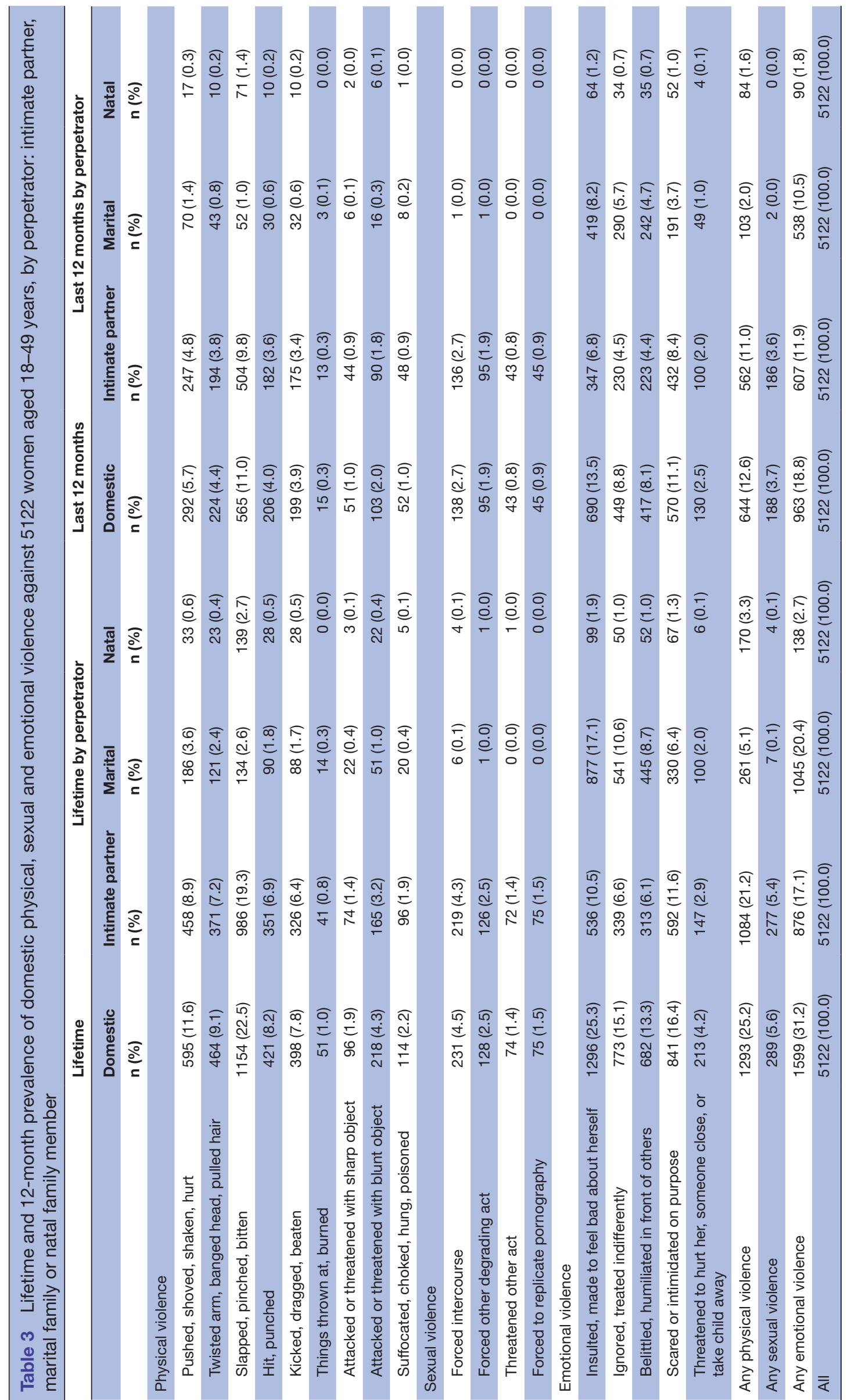




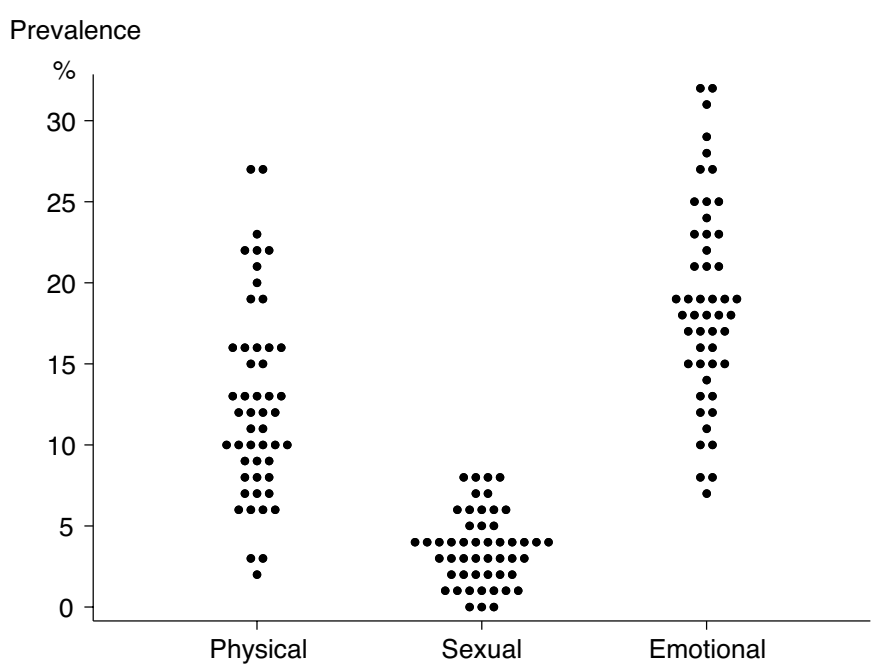

Figure 2 Prevalence of physical, sexual and emotional violence against 5122 women aged 18-49 years in 50 informal settlement clusters in Mumbai.

leaders (4\%). Even though $18 \%$ had sought medical help, only $8 \%$ had disclosed to a healthcare provider, social worker or counsellor. Twenty women approached our services for support within 2 months of the survey.

\section{DISCUSSION}

\section{Key findings}

Our cross-sectional survey of 5122 women aged 15-49 years in informal settlements in Mumbai documented high rates of domestic violence. In the preceding year, $13 \%$ of women had suffered physical violence, $4 \%$ sexual violence and $19 \%$ emotional violence. Physical and sexual violence were perpetrated mainly by intimate partners, but emotional violence was perpetrated equally by intimate partners and marital family members. Controlling behaviours were ascribed to both intimate partners and marital family members, with $35 \%$ of women reporting at least 1 of 12 restrictions.

\section{Limitations}

Our findings have three general limitations. First, although the prevalence of domestic violence was high, we should assume some under-reporting given the constellation of forces inhibiting disclosure. Second, we preferentially recruited younger, married and disabled women within households, which would tend to increase reported prevalence. Third, our study was cross-sectional and subject to the usual caveats around causal inference and the accuracy of time recall.

\section{Comparison with other studies}

We updated the review of quantitative studies by Kalokhe and colleagues, ${ }^{31}$ identifying publications from 1 January 2015 to 1 November 2019 using similar search terms, and found eight more recent published studies. The reported prevalence of domestic violence was higher in rural ${ }^{54-56}$ than in urban settings. The estimated lifetime prevalence of physical violence ranged from $18 \%^{57}$ to $27 \%,{ }^{58}$ of sexual violence from $10 \%{ }^{57}$ to $26 \%{ }^{59}$ and of emotional violence from $20 \%^{57}$ to $43 \%$ (this high estimate included questions on economic violence) ${ }^{59} \mathrm{~A}$ cross-sectional survey similar to ours, of 1137 mothers aged 18-39 years in an informal settlement in Mumbai, found a lifetime prevalence of physical intimate partner violence of $17 \%$, of emotional violence of $12 \%$ and of sexual violence of $5 \% .^{60}$

Our findings also compare with the NFHS-4 for Maharashtra state, in which estimates of prevalence of intimate partner violence were based on interviews with 2472 ever-married women aged 15-49 years. ${ }^{61}$ Both surveys estimated lifetime physical violence at $21 \%$. The NFHS-4 estimate for the last 12 months was $15 \%$ (our study $11 \%)$. We found higher prevalence of sexual $(5 \%$ ever compared with $2 \%$ in the NFHS- $4 ; 4 \%$ in the last 12 months compared with $2 \%$ ) and emotional violence ( $17 \%$ ever compared with $10 \%$ in the NFHS- $4 ; 12 \%$ in the last 12 months compared with 7\%). Our estimates of prevalence of all three types of violence were higher than those of the urban sample in the Maharashtra NFHS-4, which interviewed 1220 women (lifetime intimate partner physical violence $21 \%$ in our study, compared with $16 \%$ in the NFHS-4, sexual violence 5\% compared with $2 \%$ and emotional violence $17 \%$ compared with $9 \%$ ). There are three possible explanations for our higher estimates. First, they might be based on different sets of questions: we used similar questions and composites of them and do not think this was an issue. Second, they might reflect true population differences: our participants were all residents of informal settlements and might be more likely to face violence than the urban average. Third, women might have been more likely to disclose violence to our team of interviewers, who were backed up by a strong programme of support for survivors. It is also possible that women answer questions differently when they are responding to a survey on violence than when the questions on violence are included in a broad survey like the NFHS-4. In a consideration of methodological issues in research on intimate partner violence, Saltzman suggests that questionnaire context and cues given to the participant can influence response. ${ }^{10}$

\section{Implications}

We have a clear picture of the high burden of domestic violence against women, and of the range of findings across urban and rural settings in India. The odds of physical violence are greater for younger married women, with poorer socioeconomic position, and where underage marriage is common. ${ }^{62}$ We found that $47 \%$ of women who had suffered violence had sought help from somebody. This is considerably more than the NFHS-4, which found that $14 \%$ of urban women who had experienced physical or sexual violence had sought help from any source, usually natal family, marital family, friend or neighbour. Although disclosure to a healthcare provider, social worker or counsellor was uncommon $(8 \%)$, it 


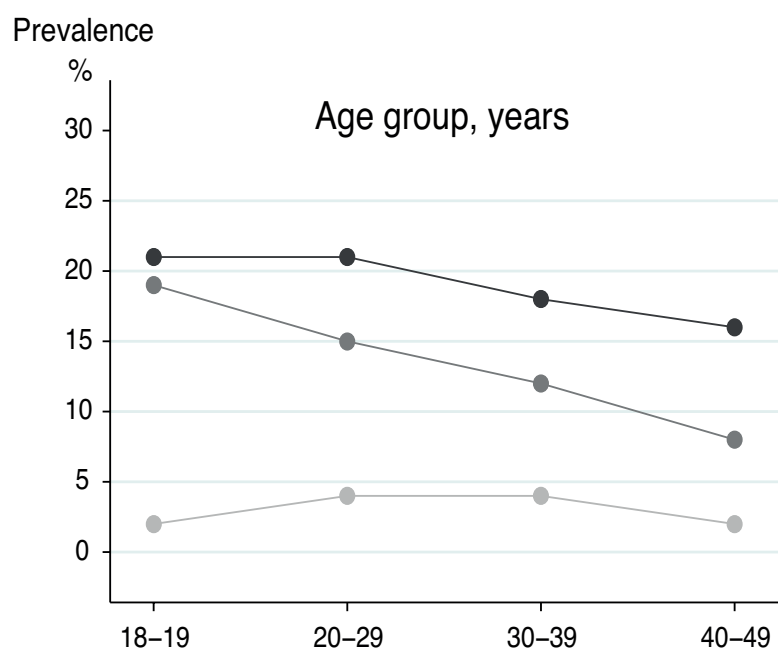

OR: univariable Odds Ratio ( $95 \%$ confidence interval) Emotional violence OR $0.84(0.76,0.94)$ Physical violence OR $0.73(0.66,0.81)$

Sexual violence OR $0.79(0.66,0.95)$

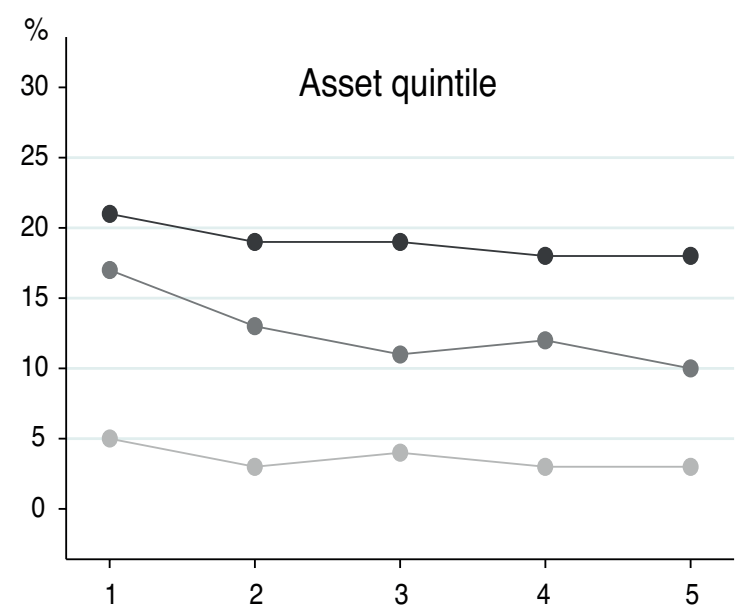

OR: univariable Odds Ratio ( $95 \%$ confidence interval) Emotional violence OR $0.95(0.90,1.01)$ Physical violence OR $0.88(0.81,0.96)$ Sexual violence OR $0.87(0.79,0.96)$
Prevalence

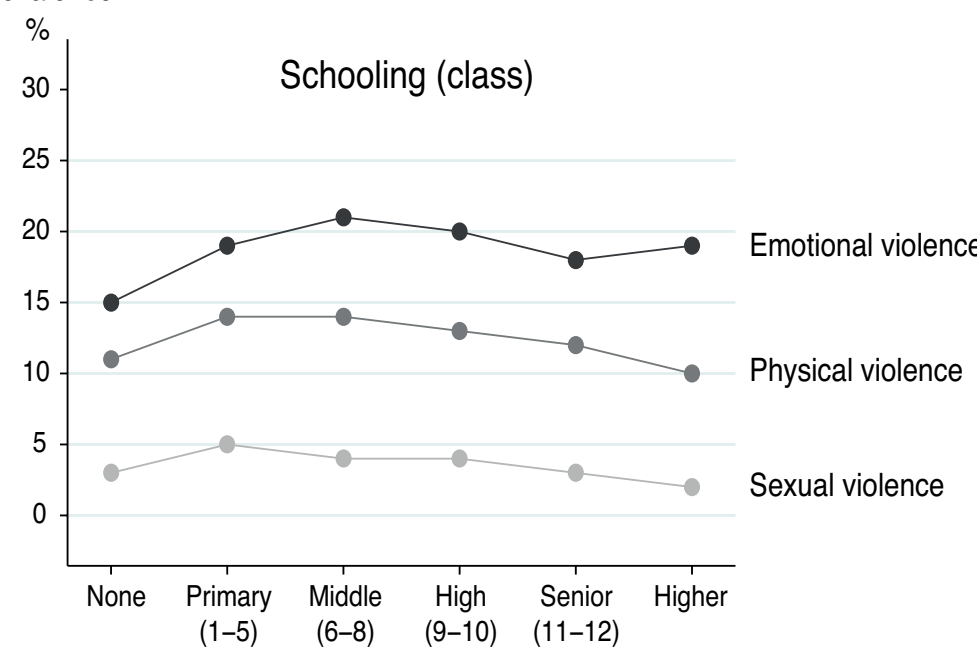

OR: univariable Odds Ratio ( $95 \%$ confidence interval)

Emotional violence OR $1.04(1.00,1.08)$

Physical violence OR $0.99(0.93,1.06)$

Sexual violence OR $0.97(0.89,1.05)$

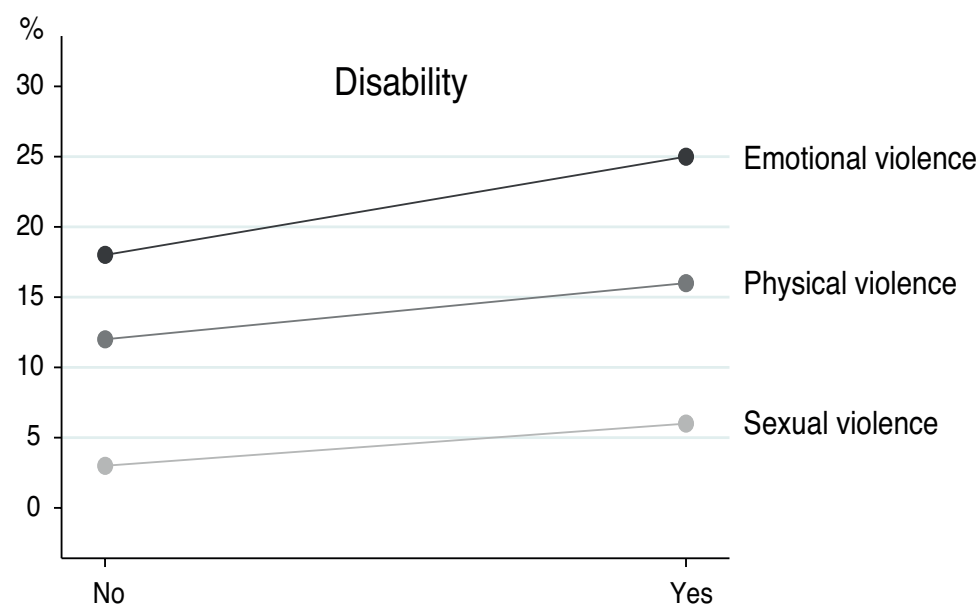

OR: univariable Odds Ratio (95\% confidence interval) Emotional violence OR $1.52(1.21,1.90)$ Physical violence OR $1.42(1.06,1.91)$ Sexual violence OR $1.93(1.24,3.02)$

Figure 3 Prevalence of physical, sexual and emotional violence against 5122 women aged 18-49 years, by age group, schooling, socioeconomic asset quintile and disability.

was also higher than the NFHS-4 urban figure of $3 \%$. Perhaps this provides some hope. Awareness of domestic violence is certainly increasing and it may be that women are becoming more confident that what they are going through is violence and that it is not acceptable.

Our particular concerns are perpetration of violence by the marital family and the burden of emotional violence and coercive control. Although only $11 \%$ of studies in the recent review considered non-partner violence, ${ }^{31}$ domestic violence by people other than intimate partners has long been a concern in the Indian context. ${ }^{63}$ Women entering the marital household are traditionally subordinate and the spectrum of violence extends from subtle neglect to dowry death. Toleration of their subservience in exchange for security and later authority over their own daughters-in-law has been described as the patriarchal bargain, ${ }^{64}$ and the burden of violence against women by mothers-in-law ${ }^{65}$ and other family members has been termed gender-based household maltreatment. It informed the design of our own questionnaire ${ }^{66}$ and includes control over reproduction, limiting contact with friends and family, and access to food. ${ }^{32}{ }^{34}$ These kinds of less visible emotional violence and control have been less well studied, but they need to be: marital family members were the source of emotional violence in about half of reports in our study and of $35 \%$ of domestic violence in rural Tamil Nadu. ${ }^{54}$ 
Table 4 Lifetime prevalence of domestic control of 5122 women aged 18-49 years, by perpetrator: intimate partner, marital family or natal family member

\begin{tabular}{|c|c|c|c|c|}
\hline Control & Domestic & Intimate partner & Marital & Natal \\
\hline & n (\%) & n (\%) & n (\%) & n (\%) \\
\hline \multicolumn{5}{|l|}{ Mobility } \\
\hline Movement always monitored & 419 (8.2) & $278(5.4)$ & $140(2.7)$ & $44(0.9)$ \\
\hline $\begin{array}{l}\text { Always prevented from attending } \\
\text { meetings }\end{array}$ & $227(4.4)$ & $129(2.5)$ & $118(2.3)$ & $5(0.1)$ \\
\hline \multicolumn{5}{|l|}{ Education } \\
\hline Prevented from schooling & $152(3.0)$ & $53(1.0)$ & $47(0.9)$ & $62(1.2)$ \\
\hline \multicolumn{5}{|l|}{ Employment } \\
\hline Prevented from seeking employment & $853(16.7)$ & $728(14.2)$ & $162(3.2)$ & $31(0.6)$ \\
\hline Coerced to seek employment & $78(1.5)$ & $42(0.8)$ & $35(0.7)$ & $7(0.1)$ \\
\hline \multicolumn{5}{|l|}{ Home dynamics } \\
\hline Excluded from family matters & $366(7.1)$ & $108(2.1)$ & $300(5.9)$ & $14(0.3)$ \\
\hline Dress or hairstyle always controlled & $267(5.2)$ & $119(2.3)$ & $145(2.8)$ & $25(0.5)$ \\
\hline Limited access to house & $173(3.4)$ & $56(1.1)$ & $137(2.7)$ & $7(0.1)$ \\
\hline Forced out of house & $165(3.2)$ & $52(1.0)$ & $121(2.4)$ & $5(0.1)$ \\
\hline Locked in house & $39(0.8)$ & $18(0.4)$ & $22(0.4)$ & $1(0.0)$ \\
\hline \multicolumn{5}{|l|}{ Health } \\
\hline Made to do excessive work & $239(4.7)$ & $39(0.8)$ & $209(4.1)$ & $11(0.2)$ \\
\hline Always requires permission for healthcare & $753(14.7)$ & $513(10.0)$ & $286(5.6)$ & $48(0.9)$ \\
\hline Any of the above & $1816(35.4)$ & $1303(25.4)$ & $830(16.2)$ & $184(3.6)$ \\
\hline All & $5122(100.0)$ & $5122(100.0)$ & $5122(100.0)$ & $5122(100.0)$ \\
\hline
\end{tabular}

Recent work on conceptualising and measuring psychological violence (here termed emotional violence) has suggested that it is distinct from controlling behaviour. ${ }^{67}$ More than one-third of women in our study reported experiencing 1 of 12 controlling behaviours and other studies have reported high levels of control by intimate partners: $72 \%$ in rural Tamil $\mathrm{Nadu}^{55}$ and $60 \%$ in rural Rajasthan, ${ }^{56}$ $43 \%$ in urban Delhi ${ }^{57}$ and $12 \%$ in Karnataka. ${ }^{68}$ In a survey of married women in Uttar Pradesh, $12 \%$ had experienced reproductive control from husbands or in-laws, with a roughly equal split between them. ${ }^{69}$

Although emotional violence and coercive control are less visible than physical violence, the gravity of their effects on women's mental health is being increasingly appreciated.$^{70}$ Follingstad et al identified six types of emotional abuse that survivors of violence in the USA had experienced: verbal attacks (ridicule, name calling, humiliation in public), isolation (social or financial), jealousy and possessiveness (including accusations of infidelity), threats of harm, threats of divorce or abandonment and destruction of personal property. All had strong negative effects on women and $73 \%$ said that emotional violence had greater impact than physical violence. ${ }^{71}$ This finding is supported by both qualitative $\mathrm{e}^{71}$ and quantitative research in high-income countries. ${ }^{73}$ In an analysis of the US National Violence Against Women Survey, psychological violence was more strongly associated with depressive symptoms than physical violence, and abuse of power and control were more strongly associated with depressive symptoms than verbal abuse. ${ }^{74}$

We are seeing similar evidence from India. In rural Rajasthan, Richardson and colleagues ' ... found evidence that psychological abuse and controlling behavior were more damaging to mental health than physical abuse' ${ }^{56}$ A cross-sectional survey of 9938 mothers aged 15-49 years in seven urban and rural locations, of whom 3155 lived in urban informal settlements, suggested that severe harassment by in-laws was associated with poor mental health. ${ }^{75}$ An analysis of follow-up data from 6303 rural married women aged 15-49 years in Bihar, Jharkhand, Maharashtra and Tamil Nadu showed a strong association between 'verbal' violence and mental health and a much weaker association with physical violence. ${ }^{76}$

\section{Generalisability}

While domestic violence is a global experience, there are differences in cultural experiences. A feature of the discussion in high-income countries from the 1970s onward was the disappointment of professional providers of support when a survivor of intimate partner violence did not leave the perpetrator. ${ }^{23247}$ The emphasis in India-on the part of survivors and professionals-has been on interventions that allow families to remain together. Tolerating domestic violence has been a normalised element of 
women's reproductive labour, ${ }^{78}$ and the ability to bear it and still fulfil the expectations of a wife and mother has been seen as praiseworthy ${ }^{80}$ and characteristic of the 'real' or 'good' woman. ${ }^{82}$ Even when domestic violence spills out into community knowledge, women who break with this tradition risk social ostracism, ${ }^{83}$ and their perceptions of their options are limited. ${ }^{2765}$

\section{CONCLUSION}

Domestic violence against women continues to be common in urban informal settlements in Mumbai and we see no reason to doubt the external validity of our findings for other locations. Physical and sexual violence are perpetrated mainly by intimate partners, but emotional violence against women is attributed equally to partners and marital family. More than one-third of women describe at least one of a limited set of controlling behaviours, perpetrated more by intimate partners, but often by marital family members.

We have two recommendations for research and action. First, social workers and healthcare providers should be aware of the importance of emotional violence and coercive control. Both are common and cause substantial suffering, particularly to women's mental health. These forms of violence need to be considered in interactions with women because of their subtlety and their intersection with poverty in urban informal settlements. Researchers should make sure that they are included in studies of domestic violence.

Second, violence is often perpetrated by family members other than intimate partners. Again, this is particularly true of emotional violence and coercive control. In interacting with clients, social workers and healthcare providers need to be aware that family members accompanying them might be involved in abuse, and studies should assume the possibility of other perpetrators.

\section{Acknowledgements Our greatest thanks go to the women and community guardians who agreed to contribute to the study. We thank the team of investigators who collected data in challenging conditions, Miheeka Vast and Manju Singh for supervising the field investigation team, Unnati Machchhar and Shilpa Adelkar for their supervision of the intervention programme, Gauri Savkur for contributing to investigator training, Bhaskar Kakad for investigator support, Archana Bagra and Vibhavari Bali for financial and human resources management, and Vanessa D'Souza and Shanti Pantvaidya for leadership at SNEHA.}

Contributors ND and DO conceived the study and acquired funding. ND, AG, SK, LG and DO developed the methodology. ND, SK and AG oversaw investigation. SK and DO curated the data. DO did the first analysis and visualisation and wrote the first draft. ND managed the project with support from SK. All authors critically reviewed the drafts of the manuscript and read and commented on the final version.

\section{Funding Wellcome Trust (206417).}

Disclaimer The funder had no role in study design, data collection and analysis, decision to publish, or preparation of the manuscript.

\section{Competing interests None declared.}

Patient and public involvement Patients and/or the public were involved in the design, or conduct, or reporting, or dissemination plans of this research. Refer to the Methods section for further details.

Patient consent for publication Not required.
Ethics approval The trial and associated data collection were approved by the Institutional Ethics Committee of Partners for Urban Knowledge, Action and Research (PUKAR) (25 December 2017) and the University College London Research Ethics Committee (3546/003; 27 September 2017). The TARA trial within which data collection took place is registered with the Controlled Trials Registry of India (CTRI/2018/02/012047; 21 February 2018) and with ISRCTN84502355 (22 February 2018: http://www.isrctn.com/ISRCTN84502355).

Provenance and peer review Not commissioned; externally peer reviewed.

Data availability statement Data are available in a public, open access repository. Data are available in Open Science Framework:0srin, D. (2020, December 5). Prevalence of domestic violence against women in informal settlements in Mumbai, India: a cross-sectional survey. Retrieved from osf.io/8y4wj

Open access This is an open access article distributed in accordance with the Creative Commons Attribution 4.0 Unported (CC BY 4.0) license, which permits others to copy, redistribute, remix, transform and build upon this work for any purpose, provided the original work is properly cited, a link to the licence is given, and indication of whether changes were made. See: https://creativecommons.org/ licenses/by/4.0/.

\section{ORCID iDs}

Lu Gram http://orcid.org/0000-0002-3905-0465

David Osrin http://orcid.org/0000-0001-9691-9684

\section{REFERENCES}

1 Ellsberg M, Jansen HAFM, Heise L, et al. Intimate partner violence and women's physical and mental health in the WHO multi-country study on women's health and domestic violence: an observational study. Lancet 2008;371:1165-72.

2 Stöckl H, Devries K, Rotstein A, et al. The global prevalence of intimate partner homicide: a systematic review. Lancet 2013;382:859-65.

3 Satyanarayana VA, Chandra PS, Vaddiparti K. Mental health consequences of violence against women and girls. Curr Opin Psychiatry 2015;28:350-6.

4 WHO. Global and regional estimates of violence against women: prevalence and health effects of intimate partner violence and nonpartner sexual violence. Geneva: World Health Organization. Report No.: $9789241564625,2013$.

5 García-Moreno C, Zimmerman C, Morris-Gehring A, et al. Addressing violence against women: a call to action. Lancet 2015;385:1685-95.

6 Solotaroff JL, Pande RP. Violence against women and girls: lessons from South Asia. Washington DC, 2014.

7 UN General Assembly. Declaration on elimination of violence against women. GA res. 48/104, 48 UN GAOR. Supp. No. 49 at 217, UN Doc. A/48/49, 1993. Available: www1.umn.edu/humanrts/instree/ e4devw.htm;

8 UNDAW. Indicators to measure violence against women. Report of the expert group meeting. Geneva: United Nations Division for the Advancement of Women, United Nations Economic Commission for Europe, United Nations Statistical Division, 2007.

9 Gelles RJ. Estimating the incidence and prevalence of violence against women. Violence Against Women 2000;6:784-804.

10 Saltzman LE. Definitional and methodological issues related to transnational research on intimate partner violence. Violence Against Women 2004;10:812-30.

11 Kilpatrick DG. What is violence against women: defining and measuring the problem. J Interpers Violence 2004;19:1209-34.

12 Heise LL. Violence against women: an integrated, ecological framework. Violence Against Women 1998;4:262-90.

13 Piedalue A. Understanding violence in place: travelling knowledge paradigms and measuring domestic violence in India. Indian J Gend Stud 2015;22:63-91. doi:10.1177/0971521514556947

14 Garcia-Moreno C, Jansen HA, Ellsberg M, et al. WHO multicountry study on women's health and domestic violence against women: initial results on prevalence, health outcomes and women's responses. Geneva: World Health Organization, 2005.

15 Johnson $\mathrm{H}$, Ollus N, Nevala S. Violence against women: an international perspective. New York NY: European Institute for Crime Prevention and Control (HEUNI), 2008.

16 Waltermaurer E. Measuring intimate partner violence (IPV): you may only get what you ask for. J Interpers Violence 2005;20:501-6.

17 Thompson MP, Basile KC, Hertz MF, et al. Measuring intimate partner violence victimization and perpetration: a compendium of assessment tools. Atlanta GA: Centers for Disease Control and Prevention, National Center for Injury Prevention and Control, 2006. 
18 Ruiz-Pérez I, Plazaola-Castaño J, Vives-Cases C. Methodological issues in the study of violence against women. $J$ Epidemiol Community Health 2007;61 Suppl 2:ii26-31.

19 Bagwell-Gray ME, Messing JT, Baldwin-White A. Intimate partner sexual violence: a review of terms, definitions, and prevalence. Trauma Violence Abuse 2015;16:316-35.

20 Straus MA. Measuring intrafamily conflict and violence: the conflict tactics (CT) scales. J Marriage Fam 1979;41:75-88.

21 Straus M, Hamby S, Boney-McCoy S, et al. The revised conflict tactics scales (CTS2) development and preliminary psychometric data. J Family Issues 1996;17:283-316.

22 Tjaden P. Defining and measuring violence against women: background, issues, and recommendations. Geneva: UN Division for the Advancement of Women, Economic Commission for Europe, World Health Organization, 2005.

23 Ferraro KJ, Johnson JM. How women experience battering: the process of victimization. Soc Probl 1983;30:325-39.

24 Mills T. The assault on the self: stages in coping with battering husbands. Qual Sociol 1985;8:103-23.

25 Decker MR, Nair S, Saggurti N, et al. Violence-related coping, help-seeking and health care-based intervention preferences among perinatal women in Mumbai, India. $J$ Interpers Violence 2013;28:1924-47.

26 Jejeebhoy SJ, Santhya KG, Acharya R. Violence against women in South Asia: the need for the active engagement of the health sector. Glob Public Health 2014;9:678-90.

27 Ragavan M, lyengar K, Wurtz R. Perceptions of options available for victims of physical intimate partner violence in northern India. Violence Against Women 2015;21:652-75.

28 Leonardsson M, San Sebastian M. Prevalence and predictors of help-seeking for women exposed to spousal violence in India - a cross-sectional study. BMC Womens Health 2017;17:99.

29 Vranda MN, Kumar CN, Muralidhar D, et al. Barriers to disclosure of intimate partner violence among female patients availing services at tertiary care psychiatric hospitals: a qualitative study. J Neurosci Rural Pract 2018;9:326-30.

30 United Nations. Convention on the elimination of all forms of discrimination against women. New York: United Nations, 1979. http://www.un.org/womenwatch/daw/cedaw/

31 Kalokhe A, del Rio C, Dunkle K, et al. Domestic violence against women in India: a systematic review of a decade of quantitative studies. Glob Public Health 2017;12:498-513.

32 Kalokhe AS, Potdar RR, Stephenson R, et al. How well does the World Health Organization definition of domestic violence work for India? PLoS One 2015;10:e0120909.

33 Silverman JG, Balaiah D, Decker MR, et al. Family violence and maltreatment of women during the perinatal period: associations with infant morbidity in Indian slum communities. Matern Child Health $J$ 2016;20:149-57.

34 Kalokhe AS, Stephenson R, Kelley ME, et al. The development and validation of the Indian family violence and control scale. PLoS One 2016;11:e0148120.

35 Ruikar MM, Pratinidhi AK. Physical wife abuse in an urban slum of Pune, Maharashtra. Ind J Public Health 2008;52:215-7.

36 Sinha A, Mallik S, Sanyal D, et al. Domestic violence among ever married women of reproductive age group in a slum area of Kolkata. Indian J Public Health 2012;56:31-6.

37 Shrivastava PS, Shrivastava SR. A study of spousal domestic violence in an urban slum of Mumbai. Int $J$ Prev Med 2013:4:27-32

38 Sabri B, Campbell JC. Intimate partner violence against women in slums in India. Indian J Med Res 2015;141:757-9.

39 UNDESA. World social report 2020: inequality in a rapidly changing world. New York NY: United Nations Department of Economic and Social Affairs. Contract No.: ST/ESA/372, 2020.

40 United Nations Human Settlements Programme (UN-Habitat). The challenge of slums: global report on human settlements 2003. London and Sterling VA: Earthscan Publications Ltd, 2003.

41 Central Bureau of Health Intelligence. National health profile 2019. New Delhi: Directorate General of Health Services, Ministry of Health and Family Welfare, Government of India, 2019.

42 Chandramouli C. Housing stock, amenities and assets in slums Census 2011. New Delhi: Office of the Registrar General and Census Commissioner, 2011. www.censusindia.gov.in

43 Daruwalla N, Machchhar U, Pantvaidya S, et al. Community interventions to prevent violence against women and girls in informal settlements in Mumbai: the SNEHA-TARA pragmatic cluster randomised controlled trial. Trials 2019;20:743.

44 Osrin D, Das S, Bapat U, et al. A rapid assessment scorecard to identify informal settlements at higher maternal and child health risk in Mumbai. J Urban Health 2011;88:919-32.
45 IIPS. National Family Health Survey 2015-16 (NFHS-4): interviewer's manual. Mumbai: International Institute for Population Sciences, 2014.

46 Washington Group on Disability Statistics (WG). Understanding and interpreting disability as measured using the Wg short set of questions. Hyattsville MD, 2009.

47 Filmer D, Pritchett LH. Estimating wealth effects without expenditure data--or tears: an application to educational enrollments in states of India. Demography 2001;38:115-32.

48 Vyas S, Kumaranayake L. Constructing socio-economic status indices: how to use principal components analysis. Health Policy Plan 2006:21:459-68.

49 Taljaard M, Weijer C, Grimshaw JM, et al. The Ottawa statement on the ethical design and conduct of cluster randomised trials: Precis for researchers and research ethics committees. BMJ 2013;346:f2838.

50 Lignou S, Das S, Mistry J, et al. Reconstructing communities in cluster trials? Trials 2016;17:166.

51 WHO. Putting women first: ethical and safety recommendations for research on domestic violence against women. WHO/FCH/ GWH/01.1. Geneva: Department of Gender and Women's Health, Family and Community Health, World Health Organization, 2001.

52 Jewkes R, Dartnall E, Sikweyiya Y. Ethical and safety recommendations for research on perpetration of sexual violence. Pretoria: Medical Research Council, Sexual Violence Research Initiative, 2012

$53 \mathrm{WHO}$. Consensus on priority indicators on violence against women Geneva, 2020. Available: https://www.who.int/reproductivehealth/ topics/violence/vaw-indicators/en/

54 George J, Nair D, Premkumar NR, et al. The prevalence of domestic violence and its associated factors among married women in a rural area of Puducherry, South India. J Family Med Prim Care 2016;5:672-6.

55 Ram A, Victor CP, Christy $\mathrm{H}$, et al. Domestic violence and its determinants among 15-49-year-old women in a rural block in South India. Ind J Commun Med 2019;44:362-7.

56 Richardson R, Nandi A, Jaswal S, et al. The effect of intimate partner violence on women's mental distress: a prospective cohort study of 3010 rural Indian women. Soc Psychiatry Psychiatr Epidemiol 2019.

57 Mukherjee R, Joshi RK. Controlling behavior and intimate partner violence: a cross-sectional study in an urban area of Delhi, India. $J$ Interpers Violence 2019;886260519876720.

58 Nadda A, Malik JS, Rohilla R, et al. Study of domestic violence among currently married females of Haryana, India. Indian J Psychol Med 2018:40:534-9.

59 Sharma KK, Vatsa M, Kalaivani M, et al. Mental health effects of domestic violence against women in Delhi: a community-based study. J Family Med Prim Care 2019;8:2522-7.

60 Begum S, Donta B, Nair S, et al. Socio-Demographic factors associated with domestic violence in urban slums, Mumbai, Maharashtra, India. Indian J Med Res 2015;141:783-8.

61 International Institute for Population Sciences (IIPS), ICF. National family health survey (NFHS-4), India, 2015-16: Maharashtra. Mumbai: IIPS, 2018

62 Ahmad J, Khan N, Mozumdar A. Spousal violence against women in India: a Social-Ecological analysis using data from the National family health survey 2015 to 2016 . J Interpers Violence 2019:088626051988153

63 Kumar V, Kanth S. Bride burning. Lancet 2004;364:18-19.

64 Kandiyoti D. Bargaining with patriarchy. Gender \& Society 1988;2:274-90.

65 Ragavan M, lyengar K. Violence perpetrated by mothers-in-law in northern India: perceived frequency, acceptability, and options for survivors. J Interpers Violence 2020;35:3308-30.

66 Ritter J, Dasgupta A, Raj A, et al. Measuring gender-based household maltreatment in urban slums of Mumbai, India. J Interpers Violence 2019:1-23:886260519864370.

67 Heise L, Pallitto C, García-Moreno C, et al. Measuring psychological abuse by intimate partners: constructing a cross-cultural indicator for the sustainable development goals. SSM Popul Health 2019;9:100377.

68 Kundapur R, Shetty SM, Kempaller VJ, et al. Violence against educated women by intimate partners in urban Karnataka, India. Indian J Community Med 2017;42:147-50.

69 Silverman JG, Boyce SC, Dehingia N, et al. Reproductive coercion in Uttar Pradesh, India: prevalence and associations with partner violence and reproductive health. SSM Popul Health 2019;9:100484.

70 Jewkes R. Emotional abuse: a neglected dimension of partner violence. Lancet 2010;376:851-2. 
71 Follingstad DR, Rutledge LL, Berg BJ, et al. The role of emotional abuse in physically abusive relationships. J Fam Violence 1990;5:107-20.

72 Vitanza S, Vogel LC, Marshall LL. Distress and symptoms of posttraumatic stress disorder in abused women. Violence Vict 1995;10:23-34.

73 Mechanic MB, Weaver TL, Resick PA. Mental health consequences of intimate partner abuse: a multidimensional assessment of four different forms of abuse. Violence Against Women 2008;14:634-54.

74 Coker AL, Davis KE, Arias I, et al. Physical and mental health effects of intimate partner violence for men and women. Am J Prev Med 2002;23:260-8.

75 Kumar S, Jeyaseelan L, Suresh S, et al. Domestic violence and its mental health correlates in Indian women. Br J Psychiatry 2005;187:62-7.

76 Stephenson R, Winter A, Hindin M. Frequency of intimate partner violence and rural women's mental health in four Indian states. Violence Against Women 2013;19:1133-50.

77 Gelles RJ. Abused wives: why do they stay. J Marriage Fam 1976;38:659-68.
78 Anitha S. Understanding economic abuse through an intersectional lens: financial abuse, control, and exploitation of women's productive and reproductive labor. Violence Against Women 2019;25:1854-77.

79 Jejeebhoy SJ, Cook RJ. State accountability for wife-beating: the Indian challenge. Lancet 1997;349 Suppl 1:S10-12.

80 Narula DK, Narula A. Patriarchal societies and domestic violence: need for empowering women. In: Charak P, Mohan C, eds. Women and development: self, society and empowerment. New Delhi: Primus Books, 2012: 169-83.

81 Ahmed-Ghosh H. Chattels of society: domestic violence in India. Violence Against Women 2004;10:94-118.

82 Jejeebhoy SJ, Santhya KG, Sabarwal S. Gender-Based violence: a qualitative exploration of norms, experiences and positive deviance. New Delhi: Population Council, 2013.

83 Ghosh S. Watching, blaming, silencing, intervening: exploring the role of the community in preventing domestic violence in India. Practicing Anthropology 2011;33:22-6. 